\title{
Features of Categorization in the Field of Subject Perception of Adult Active Internet Users
}

\section{Особенности категоризации в области предметной перцепции у взрослых активных интернет-пользователей}

\author{
Elena Medvedskaia \\ Ph.D. in Psychology, \\ Assistant Professor
}

\author{
Олена Медведська \\ кандидат психологічних наук, \\ доцент
}

E-mail:EMedvedskaja@mail.ru orcid.org/0000-0003-2033-510X

Researcher ID: M-4006-2019

\author{
Brest State University named \\ after A. S. Pushkin, Brest, \\ the Republic of Belarus \\ 21, b-rd of Cosmonauts, \\ Brest, 224016
}

Брестський державний

університет імені

О.С. Пушкіна, м. Брест, Республіка Білорусь б-р Космонавтів, 21, м. Брест, 224016

Original manuscript received April 11, 2019 Revised manuscript accepted May 10, 2019

\begin{abstract}
The article is devoted to categorization as one of the leading mechanisms of cognitive activity. Theoretical positions in the understanding of categorization are considered, the appeal to the methodology of the psycho-semantic approach in its empirical study is substantiated. A hypothesis about the complication of the categorical structure of consciousness of adult users of digital technologies due to specific characteristics of the Internet is expressed. The results of the study of the cognitive complexity of consciousness in the field of subject-sensory cognition of adult active Internet users are presented. It has
\end{abstract}


been empirically proven that they have no cognitive advantages as compared with adults who continue to use the printed word as the preferred information coding system (on a sample of 500 people over 35 years old who are knowledge workers). An explanation is offered to the recorded absence of differences in categorization through the commonality among respondents of the cultural-historical nature of the knowledge categories of the objective world and through the features of the media image as the leading coding unit of Internet information.

Key words: categorization, cognitive complexity, sign system, printed word, media image, semantic differential, factor analysis.

\section{Введение}

В современной психологии категоризация, благодаря работам Дж. Брунера и других представителей когнитивной психологии, стала одним из базовых научных понятий. Это «свойство познания вообще» (Брунер, 1977: 14); «одна из наиболее базовых функций живых организмов» (Mervis \& Rosch, 1981: 89), «основной способ организации опыта» (Лакофф, 2004: 10), «базис для построения наших знаний о мире» (Cohen \& Lefebre, 2005: 2). В отечественной психологии для обозначения этого процесса чаще используются термины «означивание» или «опосредованность значением» (Петренко, 2005).

В теоретическом понимании и эмпирическом изучении категоризации в психологии сложилось несколько подходов, основными из которых выступают классический когнитивный (Дж. Брунер) и прототипический (Э. Рош). Общим основанием названных подходов стали экспериментальные работы представителей Вюрцбургской школы, посвященные процессам перцепции и апперцепции, совокупность которых обеспечивает достаточную независимость восприятия субъекта от внешних условий. Объединяет представителей классического подхода и теории прототипов принятие базовой идеи об осуществлении восприятия в категориях.

Дж. Брунер полагал, что категоризация - это обобщение, а категорию определял через общие признаки обра- 
зующих ее объектов. «Категоризацию предмета или события - отнесение его к какому-то классу или идентификацию его - можно уподобить тому, что в теории множеств называется отнесением элемента некоего множества к некоторому его подмножеству на основе таких упорядоченных пар, троек или n признаков, как мужчина - женщина, мезоморф - эндоморф - эктоморф или, скажем, высота предмета с точностью до сантиметра» (Брунер, 1977: 14).

Дж. Брунер экспериментально доказал несколько принципиально значимых положений. Во-первых, к категоризации относится любой акт восприятия. «Если бы какое-нибудь восприятие оказалось не включенным в систему категорий, то есть свободным от отнесения к какой-либо категории, оно было бы обречено оставаться недоступной жемчужиной, жар-птицей, погребенной в безмолвии индивидуального опыта» (Брунер, 1977: 14). Этот процесс преимущественно является неосознаваемым, хотя его результат представляет собой некий логический вывод, состоящий в кодировке воспринимаемых сигналов.

Во-вторых, существует несколько типов категорий: первичные, являющиеся независимыми от опыта, и вторичные, выступающие результатом обучения в широком смысле слова. Относительно первичных, или врожденных, категорий Дж. Брунер считал их условно доказанными и относил к ним движение, причинность, тождество, намерение и др. Относительно освоения вторичных категорий он отмечал, что «обучение направлено на выделение признаков предметов, определение их значения и использование решающих признаков или сигналов, с целью группировки объектов в равноценные классы» (Брунер, 1977: 16). Таким образом, категоризация со временем совершенствуется, и это совершенствование заключается в усвоении субъектом новых систем кодирования воспринимаемой информации.

В-третьих, основной функцией категоризации Дж. Брунер считал функцию «построения модели» мира: усваивая определенные категории и их системы, субъект научается 
не только фиксировать происходящее. Благодаря категориям-обобщениям он как раз может выходить за пределы наглядно воспринимаемой ситуации, объяснять и предсказывать явления. Адекватность субъективного отражения мира обусловлена умением сопоставлять воспринимаемые признаки объектов с некоторой эталонной системой категорий, сформированной у него в итоге обобщения предшествующего опыта и нуждающейся в постоянном дальнейшем уточнении.

Продолжая развивать доказанные Дж. Брунером идеи, С. Харнад предлагает отождествлять уже не категоризацию и восприятие, но категоризацию и познавательную деятельность в целом: «познавать - значит категоризовывать: познание есть категоризация» (Harnad, 2005: 19).

Дискуссии, продолжающиеся между сторонниками когнитивного и прототипического подходов к категоризации с 70-х гг. XX в., затрагивают несколько принципиальных вопросов. Один из них - это природа категорий и их строение. В рамках когнитивного подхода этот вопрос однозначно решается в пользу дискретного строения категорий и наличия у них четких границ, в рамках прототипического подхода границы между категориями континуальны. Другой важный вопрос касается возможностей операционализации категоризации. С. Харнад (Harnad, 1990) в рамках только когнитивного подхода предлагает дифференцировать три пути изучения: моделирование посредством искусственного интеллекта, экспериментальное изучение и анализ с помощью точных психофизических методов. Таким образом, даже среди представителей одного теоретического подхода к изучению категоризации отсутствует единство мнений об эмпирических методах ее исследования.

В отечественной психологии наиболее разработанной областью науки, изучающей генезис, строение и функционирование категорий обыденного познания, является экспериментальная психосемантика. По мнению основателя 
данного направления психологии, академика В. Ф. Петренко (Петренко, 2005), психосемантика реализует субъектную конструктивистскую парадигму психологии, позволяющую обнаружить те способы познания, которыми оперирует другой субъект. В соответствии со сложившейся когнитивной традицией В. Ф. Петренко (Петренко, 2005) рассматривает категоризацию как процесс классификации, или когнитивной организации, субъектом актуально воспринимаемой информации в соответствии с уже имеющимся у него знанием. Категории как обобщенные системы значений являются тем опосредствующим звеном, через которое преломляются различные формы активности субъекта, в том числе и познавательной.

Основным методом изучения категоризации и одновременно формой модельного представления структур сознания в психосемантике выступает метод моделирования семантических пространств. Под семантическим пространством понимается особым образом структурированная система описания действительности. В. Ф. Петренко (Петренко, 2005) выделяет несколько параметров семантического пространства, каждый из которых соответствует определенному аспекту когнитивной организации сознания. Во-первых, это размерность пространства (или число независимых категорий), отражающая объем знаний или когнитивную сложность сознания субъекта в конкретной содержательной области. Во-вторых, это содержание образующих пространство категорий, которое демонстрирует ведущее основание познания действительности. В-третьих, это перцептуальная или разрешительная сила признака, по которому происходит категоризация, что говорит о субъективной значимости используемого для нее основания.

Категоризация осуществляется на нескольких уровнях. На глубинном, или простом, уровне она строится на эмоционально-оценочных основаниях, а ее итогом выступают три универсальные категории: оценка, сила и активность (пространство EPA: Evaluation - Potency - Activity) 
(Osgood, 1957). Многочисленные экспериментальные работы, проводимые с представителями различных языковых культур, разного уровня образования и категорий психического здоровья, подтвердили универсальность выделенных Ч. Осгудом (Osgood, 1957) и его сотрудниками координат человеческого сознания $\mathrm{E}-\mathrm{P}-\mathrm{A}$ : оценки, силы и активности. Инвариантность названных координат объясняется наличием уровня «глубинной семантики», на котором действует синестетический механизм категоризации. Механизм синестезии запускается на ранних стадиях презентации объекта субъекту, когда сознанию в нерасчлененном виде представлены эмоциональные и перцептивные характеристики объекта. Универсальность этого глубинного кода категоризации действительности обусловлена универсальностью человеческих эмоций, точнее их сигнальной функцией, обеспечивающей адаптацию к окружающему миру. Более сложные, развитые формы категоризации возникают по мере знакомства с некоторой содержательной областью, т. е. по мере усвоения человеком системы обобщений-эталонов, принятых в определенной культуре. Это усложнение выражается как в увеличении числа категорий, так и в изменении приниципа их организации уже не столько по коннотативным (эмоциональным), сколько по денотативным (предметным) основаниям. Таким образом, знание предмета приводит к расщеплению универсальных категорий, что делает пространство более многомерным.

Изучение категоризации в психологии проводилось на различном материале, в том числе из сферы конкретночувственного, предметого познания мира. В исследованиях Ч. Осгуда (Osgood, 1962) выделено три универсальных категории-координаты человеческого сознания - «Оценка», «Сила» и «Активность» - понятия для шкалирования были случайным образом отобраны из разных классов (ферма, стул, симфония, президент и др., всего 30). В качестве дескрипторов выступали высокочастотные прилагательные-антонимы английского языка. Позже П. Бентле- 
ру и А. Лавойе (Bentler \& Lavoie, 1972) за счет включения в набор дескрипторов прилагательных, обозначающих предметные значения, удалось дополнить это трехмерное пространство четырьмя новыми координатами:

1) сложность (составной - простой, единственный многочисленный);

2) упорядоченность (организованный - неорганизованный, постоянный - изменчивый);

3) реальность (воображаемый - действительный, абстрактный - конкретный);

4) обычность (новый - типичный, банальный - исключительный).

При этом исследователи получили высокие коэффициенты внутренней согласованности по указанным факторам (в среднем $\mathrm{r}=0,87$ ), что доказывает их стабильность.

Эта линия исследований была продолжена в российской психологии В. Ф. Петренко, который осуществлял анализ категоризации 50 понятий (из них 30 повторяли набор Ч. Осгуда) по 45 шкалам. Используемые для шкалирования понятия, как и в исследовании Ч. Осгуда, представляли разные классы (одиночество, движение, холод, патриот, мать, полицейский и др.). В итоге на материале русской лексики было подтверждено присутствие всех семи из указанных выше категорий, а также обнаружена еще одна, названная «Комфортность» (мягкий - твердый, опасный - безопасный и др.) (Петренко, 2005: 94). Ее появление В. Ф. Петренко объясняет так: «В нашем эксперименте относительно большое количество понятий, обозначающих эмоциональные состояния, привело к появлению специфического оценочного фактора «Комфортность» (Петренко, 2005: 95).

Современные исследования в области изучения индексирования значений идут в нескольких направлениях: во-первых, это линия построения частных семантических пространств для узких понятийных классов объектов; вовторых, это линия построения семантических пространств 
для однородных популяций, дифференцированных по этническому, возрастному, гендерному, профессиональному и другим критериям. Многократно экспериментально было доказано, что частные семантические пространства, хотя и сохраняют определенную преемственность по отношению к универсальному, но имеют различные размерности и различное содержание выделяемых категорий сознания, которые зависят от знаний респондентов в данной содержательной области.

Настоящее исследование продолжает линию построения частных семантических пространств для однородных групп респондентов. Оно направлено на моделирование категориальных структур знаний о предметах в сознании взрослых активных интернет-пользователей.

Медиа, породившие в конце прошедшего века Интернет, продолжают стремительно усовершенствоваться. В настоящее время речь уже идет о «новых медиа», для обозначения которых используются термины «веб нового поколения», «Web 2.0», «онлайн-медиа», «сетевые медиа». В эту группу объединяются все медиа, содержание которых может быть оцифровано и размещено в сети Интернет. А. Кирби предлагает обозначать современную культурную парадигму как дигимодернизм (или диджимодернизм), фиксируя в данном понятии влияние компьютеров на все сферы культуры (Kirby, 2009). Ученый считает оцифровывание преобладающим культурным фактором нашего времени, который постепенно все затягивает в свою орбиту и выдает уже отформатированным и отредактированным по своему образу.

Содержание этого образа в силу быстрой эволюции медиа пока остается не изученным. Идеологи Web 2.0 наряду с их техническими возможностями (оцифровка любого содержания и мгновенность его передачи на любые расстояния) отмечают также собственно психологический момент усиления веб-технологий посредством «коллективной ак- 
тивности» и «коллективного разума» их пользователей (Рейли, 2018). Это возможно благодаря таким ведущим характеристикам Web 2.0, как гипертекстовость, интерактивность (диалоговый характер потребления информации), децентрализация источников информации и, как следствие, демократизация общества в целом и сознания отдельного индивида в частности.

C психологической точки зрения вышеназванные характеристики новых медиа обеспечивают наличие у них определенного развивающего потенциала. Это позволяет предполагать, что активные интернет-пользователи будут обладать некими когнитивными преимуществами по сравнению с другими, а именно: благодаря объему и доступности web-информации они будут иметь более сложную категориальную структуру сознания, в частности, в сфере предметно-чувственного познания.

Цель исследования заключается в эмпирической проверке высказанной гипотезы о большей когнитивной сложности сознания взрослых активных интернет-пользователей в области предметной перцепции.

\section{Задача статьи}

В статье представлен сравнительный анализ категориального строя сознания (при использовании разных критериев отбора категорий) в области предметно-чувственного познания у взрослых, отдающих свои предпочтения разным системам кодирования информации: новые медиа и традиционное печатное слово.

\section{Методы и методики исследования}

В исследовании (добровольно и анонимно) приняли участие 500 взрослых (в возрасте от 35 до 60 лет), имеющих высшее образование (экономическое, юридическое, педагогическое, медицинское), работающих по специальности, проживающих в городской и сельской местности Брестской области. Сбор данных осуществлялся на протя- 
жении 2018-2019 гг. Таким образом, обобщенно выборку можно охарактеризовать как работников умственного труда, завершивших основные этапы социализации в социокультурной ситуации, которую можно охарактеризовать как доцифровую эпоху.

Общая выборка была дифференцирована на две экспериментальные группы на основании анонимного анкетирования, направленного на выявление ведущей для респондентов знаковой системы информации и ежедневные привычки обращения к различным носителям информации. Отнесение субъекта в экспериментальную группу осуществлялось на основе совпадения двух критериев:

- однозначный выбор ведущей знаковой системы в свободное время (Интернет или традиционная книга);

- большая часть свободного времени, уделяемая деятельности с этой системой.

Инструментом изучения знаний о личности был избран «один из самых информативных и универсальных методов исследования социальной перцепции» (Шмелёв, 1982: 62) - метод семантического дифференциала.

В использованном в настоящем исследовании варианте семантического дифференциала экспериментальным материалом выступали 40 шкал, обозначающих различные характеристики. При отборе шкал-дескрипторов были учтены следующие моменты. Во-первых, были заданы униполярные шкалы, поскольку их использование «дает дополнительную «степень свободы» в проекции когнитивных структур испытуемых на экспериментальный материал, так как позволяет выделить субъективную синонимию и антонимию описываемых признаков, не обязательно совпадающую с нормативно-языковой» (Петренко 2005: 206). Во-вторых, 14 из шкал были ранее заданы в предметном дифференциале Е. Ю. Артемьевой (Артемьева, 1980: 10), оставшиеся были дополнены из предметного семантического дифференциала, используемого В. Ф. Петренко 
(Петренко, 2005: 92-94) и оказавшихся ведущими в организации выделенных категорий.

По заданным шкалам семантического дифференциала по 7-балльной шкале (от 1 до 7) участникам исследования предлагалось оценить несколько предметов: стул, ручка, камень, озеро. Выбор указанных предметов обусловлен их использованием в семантическом дифференциале В. Ф. Петренко, что делает возможным сравнительный анализ, а также близостью указанных понятий непосредственному, конкретно-чувственному опыту участников исследования.

Обработка данных, полученных с помощью семантического дифференциала, осуществлялась посредством факторного анализа. Для решения задачи моделирования категориальных структур знаний о личности осуществлялось построение матрицы сходства дескрипторов при оценке одного объекта отдельно для разных экспериментальных групп (40 шкал на 100 испытуемых). Затем исходные матрицы (всего 10) подвергались процедуре факторного анализа. Факторный анализ во всех случаях осуществлялся посредством принятой в психосемантике процедуры (Петренко, 2005: 91, 98, 191): центроидный метод с извлечением главных компонент, включающий подпрограмму поворота факторных структур Varimax (программа SPSS v. 16). Образующими факторами выступали только те дескрипторы, нагрузка которых имела высокую степень статистической значимости (для 40 переменных $\mathrm{r}=0,4$ при $\mathrm{p} \leq 0,01)$.

\section{Результаты и дискуссии}

Обработка данных анкетирования позволила разделить общую выборку на три группы:

1) активные интернет-пользователи - 160 человек $(32 \%)$;

2) субъекты читающие, т. е. лица, остающиеся приверженцами традиционного печатного слова в своем выборе системы кодирования информации - 100 человек $(20 \%)$; 
3) смешанный тип, субъекты, не имеющие предпочтений знаковой системы - 240 человек (48\%).

Цель настоящего исследования предполагает сравнительный анализ, для осуществления которого был использован метод контрастных групп. Поэтому протоколы представителей смешанного типа были исключены из дальнейшей обработки.

Полученные посредством семантического дифференциала эмпирические данные позволяют решить основную задачу проведенного исследования, заключающуюся в оценке когнитивной сложности знаний о предметах окружающего мира у активных интернет-пользователей (другие параметры категориальной организации знаний, а именно содержание категорий и их валентность, представляется целесообразным исключить из обсуждения).

Как уже отмечалось, основным критерием когнитивной сложности в психосемантическом подходе к операционализации категорий сознания является количество факторов-категорий. Однако при единодушии в признании данного параметра когнитивной сложности / простоты дискуссионным остается вопрос об основаниях отбора категорий. Наиболее часто используемыми являются критерий Кайзера (или критерий собственных чисел больше единицы) и критерий Хэмфри (абсолютная величина произведения двух максимальных факторных нагрузок должна быть вдвое больше двойки, деленной на корень квадратный из количества наблюдений). Поэтому в таблице отражено количество факторов, полученных на разных критериальных основаниях.

Данные табл. 1 демонстрируют, что вне зависимости от использованного критерия отбора категорий их число для разных объектов оценивания либо одинаково, либо даже несколько выше в группе взрослых, отдающих свои предпочтения в выборе знаковой системы традиционному печатному слову. 
таблица 1

Количество факторов, организующих знания

о предметах у представителей разных групп

\begin{tabular}{|l|l|c|c|c|}
\hline \multirow{2}{*}{$\begin{array}{c}\text { Критерий } \\
\text { значимости }\end{array}$} & \multirow{2}{*}{ Группа респондентов } & \multicolumn{3}{|c|}{ Объект оценивания } \\
\cline { 2 - 5 } & Стул & Ручка & Камень \\
\hline \multirow{2}{*}{$\begin{array}{l}\text { Критерий } \\
\text { Кайзера }\end{array}$} & Субъекты читающие & 12 & 11 & 12 \\
\cline { 2 - 5 } & $\begin{array}{l}\text { Активные интернет- } \\
\text { пользователи }\end{array}$ & 10 & 11 & 12 \\
\hline \multirow{2}{*}{$\begin{array}{l}\text { Критерий } \\
\text { Хэмфри }\end{array}$} & Субъекты читающие & 0 & 2 & 1 \\
\cline { 2 - 5 } & $\begin{array}{l}\text { Активные интернет- } \\
\text { пользователи }\end{array}$ & 1 & 1 & 1 \\
\hline
\end{tabular}

Совпадение когнитивной сложности знаний о предметах у участников из разных выборок можно объяснить не только общностью непосредственного, чувственного опыта взаимодействия с предметами, являвшимися объектами оценивания. Выявленное совпадение может выступать также показателем культурно-исторической природы категорий познания предметного мира. Основанием для подобного утверждения выступают экспериментальные исследования А. Р. Лурии, посвященные изучению феномена культурной опосредованности познавательных процессов. Проведение данных исследований в 30-х гг. ХХ в. в Узбекистане и Киргизии обусловлено уникальностью сложившихся культурно-исторических условий, а именно: одновременным сосуществованием людей, как совершенно не затронутых европейским образованием, так и приобщившихся к нему в разной степени. Устойчивость и идентичность категорий мышления, обнаруженная А. Р. Лурией у людей с разной степенью образованности, по его мнению, «отражает исторически развившийся и унаследованный способ классификации предметов в окружающем нас мире» (Лурия, 1982: 50), т. к. процессы обобщения не являются «инвариантными на всех этапах социально- 
экономического и культурного развития. Такие процессы сами являются продуктами культурной среды» (Лурия, 1982: 66). Другими словами, у наших респондентов как представителей одной культуры, но отдающих предпочтение разным знаковым системам, существует общий опыт предметно-чувственного познания мира, осуществляемый в наглядно воспринимаемой ситуации. Об этом свидетельствует и отсутствие достоверных различий усредненных оценок, поставленных разным объектам в разных группах по шкалам семантического дифференциала.

Таким образом, выдвинутая гипотеза о наличии когнитивных преимуществ у пользователей Web 2.0 в области предметного познания не подтвердилась. Вероятно, объяснения данного факта следует искать не столько в возможностях Интернета, сколько в характере ведущей для данной технологии знаковой системы. В цифровой (электронной) культуре, как и в традиционной (печатной), ведущей составляющей продолжает оставаться визуальная. Однако изменяется единица кодирования информации: если традиционно ею выступало слово, то теперь оно вытесняется медиаобразом.

Основными особенностями медиаобраза (точнее, даже потока образов), выступают:

- технический характер производства и передачи;

- высокая скорость трансляции;

- мультимодальный режим передачи информации;

- преимущественно иконический характер информации;

- суггестивность воздействия.

Названные особенности образа объясняют и его психологическое воздействие (которое, кстати, не-психологами тоже описывается очень образно и метафорично): «бомбардировка» сознания образами (Э. Тоффлер), «захват сознания» (М. Маклюэн), «ослепляющий поток» образов (M. Кастельс), «навязывающий» ящик (Д. Рашкофф) и др. Помимо того, что этот поток преимущественно воздействует на 
зрение как на главный орган восприятия информации, его еще можно считать экологичным содержанию сознания человека, которое в эмпирическом опыте предстает как «непрерывно меняющаяся совокупность чувственных и умственных образов, непосредственно предстающих перед субъектом в его “внутреннем опыте” и предвосхищающих его практическую деятельность» (Петровский, Ярошевский, 1990: 368-369). Однако неестественные и постоянно наращиваемые скорость и мощность потока медиаобразов, вероятно, вызывают и определенные «сдвиги» в сознании и его функционировании, делая его менее способным к концентрации на предмете, целеполаганию и планированию, к остановке и критическому анализу.

Произошедшая в последние десятилетия «цифровая революция» буквально на глазах трансформировала практически все области социальной практики в цифровую повседневность. Однако с ее наступлением явно смещаются акценты в обращении к электронным технологиям. Если первоначально возможности компьютера и Интернета использовались с позиции извне, для решения конкретных задач (увеличение точности расчетов и объема информации, ускорение темпа передачи и др.), то в настоящее время пользователи преимущественно находятся в позиции внутри, они включены в информационный поток. И поэтому вовлечены не столько в его содержание, сколько в процесс регулирования (нажимать на кнопки, реагировать на всплывающие окна и сообения, блокировать и т. п.). Иначе говоря, приоритетными в практике становятся не столько целенаправленный поиск и обработка информации (и, соответственно, итог данного процесса - приращение знаний), сколько удобство и комфортность ее получения. Подобное смещение акцентов вполне закономерно приводит к тому, что оптимистические ожидания как в отношении телевидения (как средства когнитивного развития зрителей), так в отношении Интернета (как глобальной интеллектуальной лаборатории, предназначенной для произ- 
водства нового знания) на практике стихийным образом не реализуются.

\section{Заключение}

В области предметно-чувственного познания взрослые активные интернет-пользователи не демонстрируют большей когнитивной сложности по сравнению с любителями традиционного чтения. Это доказывает, что у экрана монитора не происходит совершенствования категоризации, т. е. благодаря новым цифровым технологиям у их пользователей не формируются непроизвольным образом новые системы кодирования воспринимаемой информации о предметном мире.

Особенности медиобраза, как ведущего знака кодирования информации в интернет-технологии, оставляют пользователя в рамках наглядной ситуации, что не позволяет процессу категоризации реализовывать свои основные функции объяснения и предсказания действительности.

Полученные эмпирические данные позволяют утверждать, что само погружение субъекта в интенсивный информационный поток не приводит к автоматическому приращению у него знаний, не усложняет сложившуюся категориальную структуру сознания (не исключено, что даже и упрощает). Даже взрослым, занятым интеллектуальными видами труда, требуются специальные усилия для преобразования информации в знания.

\section{Литература}

Артемьева Е. Ю. Психология субъективной семантики. Москва : МГУ, 1980. $128 \mathrm{c}$.

Брунер Дж. Психология познания. Москва : Прогресс, 1977. 414 с.

Лакофф Дж. Женщины, огонь и опасные вещи: Что категории языка говорят нам о мышлении. Москва : Языки славянской культуры, 2004. $792 \mathrm{c}$.

Лурия А. Р. Культурные различия и интеллектуальная деятельность Этапы пройденного пути: научная автобиография / Под ред. Е. Д. Хомской. Москва : МГУ, 1982. С. 47-69. 
O’Рейли Т. Что такое Веб 2.0? [Электронный ресурс]. URL : http://www. computerra.ru/think/234100/. Дата доступа: 20.05.2018.

Петренко В. Ф. Основы психосемантики. Санкт-Петербург : Питер, 2005. $480 \mathrm{c}$.

Психология: словарь / Под ред. А. В. Петровского, М. Г. Ярошевского. Москва : Политиздат, 1990. 494 с.

Шмелёв А. Г. Об устойчивости факторной структуры личностного семантического дифференциала. Вестник МГУ. Сер. 14. Психология. 1982. № 2. С. 62-65.

Bentler, P. M., \& Lavoie, A. L. (1972). An Extension of semantic Space. Journal of Verbal Learning and Verbal Behaviour, 109, 123-144.

Cohen, H., \& Lefebre, C. (2005). Bridging the category divide. Handbook of categorization in cognitive science. Montreal : Elselvier, pp. 1-15.

Harnad, S., Cohen, H., \& Lefebre, C. (2005). To cognize is to categorize: cognition is categorization. Handbook of categorization in cognitive science. Montreal : Elsevier, pp. 20-42.

Harnad, S. (1990). Psychophysical and cognitive aspects of categorical perception: a critical overview. Categorical perception: the groundwork of cognition. New York : Cambridge University Press, pp. 1-28.

Kirby, A. (2009). Digimodernism: How New Technologies Dismantle the Postmodern and Reconfigure Our Culture. New York : Continuum Publishing Corporation.

Mervis, C. B., \& Rosch, E. (1981). Categorization of natural objects. Annual Review of Psychology, 32, 89-115.

Osgood, C. E., Suci, G., \& Tannenbaum, P. (1957). The measurement of meaning. Chicago \& London : University of Illinois Press.

Osgood, C. E. (1962). Studies on generality of affective meaning system. Amer. Psychologist, 17, 10-28.

\section{References}

Artemjeva, E. Ju. (1980). Psihologija subjektivnoj semantiki [Psychology of subjective semantics]. Moskva : MGU [in Russian].

Bruner, Dzh. (1977). Psihologija poznanija [Psychology of knowledge]. Moskva : Progress [in Russian].

Lakoff, Dzh. (2004). Zhenshchiny, ogon' i opasnye veshchi: Chto kategorii jazyka goworjat nam o myshlenii [Women, fire and dangerous things: what categories of language tell us about thinking]. Moskva : Jazyki slavjanskoj kul'tury [in Russian].

Lurija, A. R. (1982). Kul'turnye razlichija i intellektual'naja dejatel'nost' [Cultural differences and intellectual activity]. E. D. Khomskaia (Ed.). Jetapy projdennogo puti - Stages of travelled distance. Moskva : MGU [in Russian].

O'Reili, T. (2018). Chto takoe Veb 2.0? [What is Web 2.0?]. Retrieved from http://www.computerra.ru/think/234100/ [in Russian]. 
Petrenko, V. F. (2005). Osnovy psihosemantiki [Basics of psychosemantics ]. Sankt-Peterburg : Piter [in Russian].

Petrovskij, A. V., \& Jaroshevskij, M. G. (Eds.). (1990). Psihologija: slovar' [Psychology: dictionary]. Moskva : Politizdat [in Russian].

Shmelev, A. G. (1982). Ob ustojchivosti faktornoj struktury lichnostnogo semanticheskogo differentsiala [On the stability of the factor structure of the personal semantic differential]. Vestnik MGU - Bulletin of Moscow State University. Series 14. Psychology, 2, 62-65 [in Russian].

Bentler, P. M., \& Lavoie, A. L. (1972). An Extension of semantic Space. Journal of Verbal Learning and Verbal Behaviour, 109, 123-144.

Cohen, H., \& Lefebre, C. (2005). Bridging the category divide. Handbook of categorization in cognitive science. Montreal : Elselvier.

Harnad, S., Cohen, H., \& Lefebre, C. (2005). To cognize is to categorize: cognition is categorization. Handbook of categorization in cognitive science. Montreal : Elsevier.

Harnad, S. (1990). Psychophysical and cognitive aspects of categorical perception: a critical overview. Categorical perception: the groundwork of cognition. New York : Cambridge University Press.

Kirby, A. (2009). Digimodernism: How New Technologies Dismantle the Postmodern and Reconfigure Our Culture. New York : Continuum Publishing Corporation.

Mervis, C. B., \& Rosch, E. (1981). Categorization of natural objects. Annual Review of Psychology, 32, 89-115.

Osgood, C. E., Suci, G., \& Tannenbaum, P. (1957). The measurement of meaning. Chicago \& London : University of Illinois Press.

Osgood, C. E. (1962). Studies on generality of affective meaning system. Amer. Psychologist, 17, 10-28.

\section{Медведська Олена. Особливості категоризації в сфері предметної перцепції у дорослих активних інтернет-користувачів}

\section{Анотація}

Статтю присвячено категоризації як одному з провідних механізмів пізнавальної діяльності. Розглянуто теоретичні позиції у розумінні категоризації, обгрунтовано звернення до методології психосемантичного підходу в ії емпіричному вивченні. Висловлено гіпотезу про ускладнення категоріальної структури свідомості у дорослих користувачів цифрових технологій, обумовлене специфічними характеристиками Iнтернету. Представлено результати вивчення когнітивної складності свідомості у сфері предметно-чуттєвого пізнання в дорослих активних інтернет-користувачів. Емпірично доведено, що вони не мають ні- 
яких когнітивних переваг порівняно з дорослими, які продовжують використовувати друковане слово в якості бажаної системи кодування інформації (на вибірці з 500 осіб, старших 35 років, які є працівниками розумової праці). Запропоновано пояснення зафіксованій відсутності відмінностей в категоризації у зв'язку зі спільністю у респондентів культурно-історичної природи категорій пізнання предметного світу й особливостями медіаобразу як провідної одиниці кодування інтернет-інформації.

Ключові слова: категоризація, когнітивна складність, знакова система, друковане слово, медіаобраз, семантичний диференціал, факторний аналіз.

Медведская Елена. Особенности категоризации в области предметной перцепции у взрослых активных интернет-пользователей

\section{АННОТАЦИЯ}

Статья посвящена категоризации как одному из ведущих механизмов познавательной деятельности. Рассмотрены теоретические позиции в понимании категоризации, обосновано обращение к методологии психосемантического подхода в ее эмпирическом изучении. Высказана гипотеза об усложнении категориальной структуры сознания у взрослых пользователей цифровых технологий, обусловленная специфическими характеристиками Интернета. Представлены результаты изучения когнитивной сложности сознания в области предметно-чувственного познания у взрослых активных интернет-пользователей. Эмпирически доказано, что они не имеют никаких когнитивных преимуществ по сравнению со взрослыми, продолжающими использовать печатное слово в качестве предпочитаемой системы кодирования информации (на выборке из 500 человек, старше 35 лет и являющихся работниками умственного труда). Предложено объяснение зафиксированному отсутствию различий в категоризации через общность у респондентов культурно-исторической природы категорий познания предметного мира и через особенности медиаобраза как ведущей единицы кодирования интернет-информации.

Ключевые слова: категоризация, когнитивная сложность, знаковая система, печатное слово, медиаобраз, семантический дифференциал, фракторный анализ. 